\title{
Medievalista
}

Online

25 | 2019

Número 25

\section{Mutação Urbana na Lisboa Medieval. Das Taifas a D. Dinis}

Tese de Doutoramento em História Medieval apresentada na Faculdade de Letras da Universidade de Lisboa, Agosto de 2017. Orientação do Professor Doutor Hermenegildo Goinhas Fernandes e co-orientação da Professora Doutora Maria João Branco

Manuel Fialho Silva

\section{(2) OpenEdition}

\section{Journals}

Edição electrónica

URL: http://journals.openedition.org/medievalista/1777

DOI: $10.4000 /$ medievalista. 1777

ISSN: 1646-740X

\section{Editora}

Instituto de Estudos Medievais - FCSH-UNL

\section{Refêrencia eletrónica}

Manuel Fialho Silva, « Mutação Urbana na Lisboa Medieval. Das Taifas a D. Dinis », Medievalista [Online], 25 | 2019, posto online no dia 17 março 2019, consultado o 23 setembro 2020. URL : http:// journals.openedition.org/medievalista/1777 ; DOI : https://doi.org/10.4000/medievalista. 1777

Este documento foi criado de forma automática no dia 23 setembro 2020.

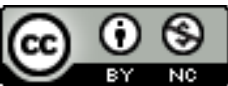

Mediavalista está licenciado com uma Licença Creative Commons - Atribuição-NãoComercial 4.0 Internacional. 


\section{Mutação Urbana na Lisboa Medieval. Das Taifas a D. Dinis}

Tese de Doutoramento em História Medieval apresentada na Faculdade de Letras da Universidade de Lisboa, Agosto de 2017. Orientação do Professor Doutor Hermenegildo Goinhas Fernandes e co-orientação da Professora Doutora Maria João Branco

\section{Manuel Fialho Silva}

\section{NOTA DO EDITOR}

Data recepção do artigo / Received for publication: 06-11-2018

1 Ter Lisboa como alvo da Tese de Doutoramento Mutação Urbana na Lisboa Medieval. Das Taifas a D. Dinis assentou em diversos factores, não sendo alheias questões mundanas como o ser a cidade onde cresci, nasci e à qual dedico o meu trabalho de investigação nas instituições a que estou vinculado profissional e academicamente. Além disso, importa sublinhar que o tema central que me propus abordar não estava ainda esgotado. Os limites cronológicos, entre o período de taifas (século XI) e o reinado de D. Dinis (1325), momentos estruturantes no que respeita à evolução urbana da cidade, foram objectivamente enquadrados no processo de transição entre o domínio político muçulmano e o cristão. No primeiro destes momentos, o século XI, ocorreu uma intensa remodelação urbana em algumas partes da cidade, tal como no tempo de D. Dinis, em cujo reinado ficou definida a compleição da cidade medieval, pois durante este último período ocorreram intervenções na cidade que a marcariam até ao terramoto ocorrido a 1 de Novembro de 1755.

2 A tese insere-se em duas áreas de estudo que muitas vezes se confundem: História Urbana e História do Urbanismo. Com consciência das diferenças que possuem entre si, optou-se por abordar ambos os temas. Assim, a investigação focou-se, por um lado, no modo como se estrutura o espaço urbano, ou seja, na História do Urbanismo medieval de Lisboa; por outro, já no campo da História Urbana, procurou-se formular um 
panorama transversal da evolução da forma da cidade, considerando não apenas o cenário, mas também os actores que o modelam e, além disso, o contexto onde decorrem as acções de transformação urbana. Quanto à metodologia, deve referir-se que se fundamentou na multidisciplinaridade atentando, por isso, a diversas áreas, onde importa destacar as seguintes: História, Arqueologia, Cartografia e Iconografia.

O estudo do processo histórico constituiu o alicerce desta tese, pois a análise da documentação medieval foi o primeiro e mais fundamental passo aqui tomado. Os dados relevantes, patentes na referida documentação, foram organizados e processados numa folha de dados para possibilitar uma rápida e eficaz consulta de uma grande quantidade de informação. Além disso, do ponto de vista da Arqueologia, que desempenhou um papel igualmente determinante, procedeu-se quer à pesquisa de sítios arqueológicos com informação relevante para o período cronológico considerado, quer à análise dos processos onde se inserem os relatórios das referidas escavações. Esta análise compreendeu a consulta no Arquivo de Arqueologia Portuguesa situado no Palácio da Ajuda e a realização de entrevistas pessoais a alguns arqueólogos responsáveis por escavações onde foi possível obter informação relevante para o período e área em causa.

4 A Cartografia e a Iconografia foram objecto de uma metodologia semelhante à descrita. Foram feitas pesquisas no sentido de se tomar conhecimento e, sempre que possível, obter cópias digitais, da cartografia e iconografia que permitissem a reconstituição da cidade medieval. Deve ressalvar-se que não chegou aos nossos dias documentação cartográfica ou iconográfica coeva, o que obrigou à consideração de material mais tardio mas que, ainda assim, se revelou fundamental para a concepção das plantas apresentadas nesta tese, cuja base principal foi a Planta Topográfica da Cidade de Lisboa compreendendo na sua extensão a beira mar da Ponte d'Alcantara até ao Convento das Comendadeiras de Santos, de autor anónimo, cuja cópia existe no Gabinete de Estudos Olisiponenses. Esta fonte foi tratada retirando camadas de informação até se obter uma representação aproximada da cidade em época medieval. Em sentido oposto, os dados foram articulados e inseridos com os obtidos na análise à documentação e aos dados das escavações arqueológicas.

O estudo que aqui se apresenta foi organizado em cinco partes intrinsecamente relacionadas com a estrutura topográfica da cidade medieval: Medina, Alcáçova, Arrabalde Oriental, Arrabalde Ocidental e Arrabalde dos Mouros. A estruturação topográfica teve como objectivo, em primeiro lugar, possibilitar uma leitura cronológica contínua da evolução urbana de cada parte e, em segundo, uma compreensão de cada segmento mantendo-se a coesão do todo. No prólogo abordam-se três temas que funcionam como átrio de acesso à tese que foram apartados do corpo principal do texto, uma vez que a sua natureza exordial não se inseria na referida organização topográfica. Os dois primeiros capítulos do prólogo conduzem a uma observação transversal que ultrapassa os limites físicos e cronológicos do trabalho, pois incluem não só a cidade da foz do Tejo, mas também outras urbes do Mediterrâneo e do Magreb e períodos históricos anteriores ao século XI. O terceiro capítulo do prólogo versa sobre o processo de implantação da rede paroquial que ocorreu na cidade após 1147 , contemplando a cidade no seu conjunto. 


\section{Da Medina à Cidade}

6 A primeira parte do corpo da tese foi dedicada à análise da secção intramuros da cidade. A investigação indicou que o principal aspecto definidor da morfologia urbana desta parte da cidade foi a topografia do terreno e que, por esse motivo, a forma da cidade intramuros se organizava em patamares. Aqui foram tratadas algumas intervenções que desequilibraram a estreita relação entre a cidade e a colina: a construção do teatro romano, considerada de forma sucinta, pois escapa à cronologia; a construção da cerca urbana, principal estrutura defensiva da cidade até 1373; a construção da Sé no século XII; o aterro e a construção do claustro da Sé, em finais do século XIII ou no início do século XIV. Foi também encarada a possibilidade de ter existido, em época de domínio islâmico, um suq intramuros, que se situaria entre a Mesquita Maior, ou seja, o local onde posteriormente se implantou a Sé, e a Porta do Ferro. Confirmou-se também uma importante ligação entre os principais eixos viários e a acidentada orografia do terreno, observável nos pontos de acesso da cerca urbana, isto é, no posicionamento das portas da muralha. o patamar superior desenvolvia-se em torno da via que ligava as duas portas mais altas da cidade intramuros, a porta do Sol e a porta da Alfôfa. O patamar intermédio abrangia toda a malha urbana que se desenvolvia em torno dos dois principais eixos que seccionavam a Medina, formando um "Y", ligando as portas orientais, do Sol e de Alfama à porta ocidental, também conhecida como Porta do Ferro. Por fim, o patamar inferior integrava a malha urbana ribeirinha, tendo como eixo organizador o rio Tejo.

\section{A Alcáçova}

7 A segunda parte da tese trata a evolução urbana da Alcáçova. Foi formulada uma proposta sobre a ocorrência de uma importante remodelação desta área da cidade em meados do século XI, onde se destacam a formação da Alcáçova, a construção do Castelejo e também a do bairro residencial na Praça Nova. Relativamente à presença almorávida propõe-se que não tenha produzido alterações significativas na estrutura urbana herdada da época de taifas, modificando apenas e superficialmente alguns aspectos da vivência urbana, perceptíveis no bairro residencial da Praça Nova. Após a tomada da cidade, em 1147, as estruturas urbanas foram adaptadas à nova realidade política e cultural: os pátios centrais perderam a sua função como centro das habitações e abriram-se novas portas e janelas nas fachadas. No entanto, várias estruturas da Alcáçova mantiveram a mesma função: o castelejo manteve a vocação militar, a mesquita provavelmente deu lugar a uma igreja e é possível que o Palácio do Alcaide se tenha tornado num paço real. A análise documental revelou que os primeiros topónimos identificáveis com algumas ruas que ainda marcam a actual morfologia urbana da Alcáçova terão surgido no reinado de D. Dinis.

\section{O Arrabalde Ocidental}

O Arrabalde Ocidental foi a parte da cidade em que a investigação foi mais frutífera, pois os dados obtidos possibilitaram várias propostas, o que favoreceu a compreensão sobre a evolução morfológica da cidade medieval. Em finais do domínio islâmico, já no séc. XII, o Arrabalde Ocidental teria cerca de 16,7 hectares de área urbana, números que 
se assemelham à área da cidade intramuros. A Judiaria Grande, possivelmente herdeira de uma judiaria de época islâmica, apresentava um urbanismo marcado pela matriz mediterrânica, muito diverso do urbanismo linear presente na Judiaria Pequena, erguida por D. Dinis. A pesquisa documental conjugada com a análise dos resultados das escavações arqueológicas revelou uma notável regressão urbana após a conquista de 1147, no Arrabalde Ocidental, mais marcada a norte, e menos marcada junto à área ribeirinha. Deste modo, verificou-se que apenas no século XIV foi reurbanizada parte considerável do arrabalde que existia antes da conquista. Nesta parte da tese, foi proposta a existência de um suq do arrabalde, em época de domínio islâmico, na principal artéria que deixava a principal porta ocidental da cidade em direcção a norte, a posterior Correaria. Relativamente ao período pós 1147, verificou-se a existência de um importante pólo comercial na Correaria, documentado em meados do século XIII. Foi também considerada a criação de um novo pólo comercial na Ribeira, o qual se tornará gradualmente o epicentro da vida social e comercial da cidade, impondo-se sobre o antigo pólo da Correaria. Este processo de deslocação do centro comercial iniciou-se no reinado de Afonso III, com a criação do quarteirão das Fangas e Carniçarias, ficando plenamente consolidado no reinado de D. Dinis, com a remodelação urbana da Ribeira, nomeadamente através da edificação da fachada sul da Rua Nova e da Rua da Ferraria. Ainda na parte sobre o Arrabalde Ocidental, foi observada (inserida neste mesmo plano de restruturação da Ribeira) a génese do edifício das tercenas régias, situado no extremo ocidental do arrabalde. Note-se que esta estrutura militar, a mais relevante do reino no que respeita à manutenção e construção da frota naval portuguesa, perdurou até ao século XV. A evolução urbana da Pedreira revelou como D. Dinis deu um primeiro passo na urbanização deste espaço com a construção de casas que albergaram brevemente o Estudo Geral, erguidas segundo o modelo do lote estreito, típico do período.

Relativamente à reestruturação da Ribeira ocorrida no reinado de D. Dinis, confirmouse uma extraordinária continuidade da forma urbana entre a época medieval e o século XVIII. Esta proposta assenta no facto de que a reconstituição de Augusto Vieira da Silva da fachada sul da Rua Nova, realizada com base numa fonte documental muito fiável, o Tombo de Lisboa, apresenta o mesmo número de lotes (47) que o Livro dos bens Próprios escrito entre 1299 e 1300.0 mesmo número de lotes foi ainda confirmado na pintura da Rua Nova dos Mercadores realizada no século XVI e recentemente encontrada em Inglaterra, ratificando as informações documentais.

\section{O Arrabalde Oriental}

10 A investigação sobre o Arrabalde Oriental também trouxe, por sua vez, novas propostas. Sobre a dimensão do arrabalde em época islâmica, tendo como base as descrições dos geógrafos árabes e os resultados das escavações arqueológicas, sugere-se que este poderia abarcar, na área ribeirinha, o espaço entre a Porta de Alfama e a Rua da Regueira, talvez chegando mesmo às Portas da Cruz. Todavia, relativamente à área superior não existem dados documentais, nem escavações arqueológicas que permitam conceber uma proposta sólida sobre a área urbanizada. Em época islâmica, o arrabalde Oriental seria, à semelhança do Ocidental, um espaço multifuncional, onde as funcionalidades habitacionais e artesanais se combinavam sem grandes obstáculos. Escavações arqueológicas permitiram identificar vestígios de estruturas habitacionais, 
olarias, sistemas de condução de água, um poço, um celeiro, lixeiras, silos, construções de armazenamento e necrópoles. No que respeita às alterações urbanísticas na transição entre o domínio islâmico e o cristão, a casa encontrada no pátio da FRESS demonstra de forma exemplar o que terá ocorrido no período: a extinção do pátio central e a substituição dos acessos em adarves por acessos em fachada. Transpor as mudanças dessa casa para o urbanismo da cidade em geral permite compreender melhor a ausência de estruturas de pátio central na cidade moderna (e até na actual), mantendo-se, nos casos onde o urbanismo medieval não foi erradicado, uma configuração complexa do sistema viário, como acontece em Alfama. Situado nos limites do Arrabalde Oriental, o Mosteiro de S. Vicente funcionou como uma força de bloqueio ao crescimento urbano devido à grande abrangência da sua área de influência directa. A par da ampla influência exercida pelo Mosteiro de S. Vicente, verificou-se a presença de um relevante núcleo de propriedades régias no extremo oriental do arrabalde onde no reinado de D. Dinis existiu uma Casa da Moeda, possivelmente o Estudo Geral, um rossio, e ainda um vasto campo e olival.

\section{O Arrabalde dos Mouros}

11 O estudo do Arrabalde dos Mouros levantou várias questões, sendo de destacar a origem da Mouraria: terá a Mouraria de Lisboa surgido em 1147 ou em meados do século XIII? A proposta é a de que a Mouraria, como espaço físico organizado, terá apenas surgido nos meados do século XIII, pois o foral de 1170 concedido aos mouros forros de Lisboa, Almada, Palmela e Alcácer não refere a instituição de uma Mouraria em qualquer destas cidades e, além disso, a primeira referência documental inequívoca ao seu aparecimento data de 1263. Na reconstituição da Mouraria evidenciam-se dois elementos delimitadores: por um lado o almocávar, por outro, a área de Benfica, uma zona marcada por explorações agrícolas de pequena dimensão, ou seja, por propriedade alodial muçulmana e por almuinhas.

\section{Conclusões}

12 A principal conclusão que a investigação permitiu prende-se com uma nova percepção da evolução do urbanismo da cidade medieval e do papel que teve no desenho urbano da Lisboa pós-medieval. Deste modo, tornou-se perceptível que a Lisboa do final do reinado de D. Dinis apresentava dois traços fundamentais que iriam marcar a sua forma urbana posterior:

- O crescimento em direcção a Ocidente

- O centro económico e social já consolidado na Ribeira

13 Também se avança com a proposta de que o século XI foi um tempo de alterações profundas na morfologia urbana da cidade, proposta esta assente nos resultados de várias escavações arqueológicas que apontam esta data como um momento de remodelação. Neste período terá ocorrido a delimitação do espaço da Alcáçova, a construção do bairro residencial no mesmo local, a construção de um edifício público no centro da Medina (claustro da Sé), a repavimentação da via norte (posterior Corredoura) e um incremento da urbanização do arrabalde ocidental. Os dados das escavações arqueológicas, observados no seu conjunto, permitiram afirmar que o 
Arrabalde Ocidental já se impunha nesta época como uma zona de forte desenvolvimento urbano. cristão foram diversas e ocorreram em sentidos distintos, quer no da ruptura, quer no da continuidade. Na perspectiva da ruptura, os muçulmanos abandonaram a medina e a alcáçova para aí se instalarem os novos habitantes cristãos. A maioria habitações foram provavelmente reconfiguradas pelos seus novos ocupantes, desaparecendo gradualmente os pátios centrais, abandonando-se os acessos em adarves para dar lugar a acessos nas fachadas, factores que alteraram o urbanismo da cidade. Nos arrabaldes, várias olarias foram então abandonadas e provavelmente deslocadas. A rotura mais significativa terá sido a inversão do crescimento urbano que a cidade conheceu até 1147, ocorrendo uma relevante regressão, bem identificável nos arrabaldes. No sentido da continuidade, foi assinalada a persistência na funcionalidade de várias estruturas: templos convertidos e estruturas militares.

No que respeita ao impacto que os primeiros monarcas portugueses tiveram na evolução urbana da cidade destacam-se os reinados de Afonso III e seu filho D. Dinis. Afonso III iniciou um processo organizado de aproximação do centro económico-social em direcção à Ribeira, pois o anterior centro situava-se na estrutura viária que saía da Porta do Ferro e abrangia a Rua da Correaria até à igreja de S. Nicolau, possivelmente herdeiro de um suq de arrabalde, de época de domínio islâmico. Através de um colossal processo de aquisição de propriedade urbana na área correspondente ao anterior centro económico da cidade, conjugado com a fixação de várias estruturas na Ribeira, Afonso III deslocou definitivamente o centro económico da urbe para a margem ribeirinha do Arrabalde Ocidental, local já então denominado por Ribeira. D. Dinis continuou o processo iniciado pelo seu pai através de um muito hábil plano de urbanização que teve a construção da muralha da Ribeira como principal móbil, mas cujo alcance foi muito para além da simples construção de uma estrutura defensiva. A muralha da Ribeira foi construída, não só para cumprir uma funcionalidade defensiva, mas sobretudo para possibilitar a edificação de dois eixos que se revelariam fundamentais na vida económica e social da cidade até ao dia 1 de Novembro de 1755: a Rua Nova e a Rua da Ferraria. Nestes dois eixos viários foi implantado um número considerável de lotes, determinados por medidas-padrão, indicadores de um planeamento urbanístico onde foi aplicada a técnica do cordeamento, documentada pela primeira vez em território português. As áreas dos lotes configurados por D. Dinis nestas artérias chegaram ao século XVIII, tendo desaparecido da forma urbana da cidade após o terramoto de 1755, factor que demonstra cabalmente a relevância da Lisboa medieval na formação do tecido urbano da cidade posterior. 


\section{AUTOR}

\section{MANUEL FIALHO SILVA}

Centro de História, Faculdade de Letras, Universidade de Lisboa, 1600-214 Lisboa, Portugal Gabinete de Estudos Olissiponenses da Câmara Municipal de Lisboa, 1500-100 Lisboa, Portugal manuel.fialho@cm-lisboa.pt https://orcid.org/0000-0002-1991-5396 